\title{
Parents and partners in crime: a six-year longitudinal study on changes in supportive relationships and delinquency in adolescence and young adulthood
}

\author{
W. Meeus, S. Branje, and G.J. Overbeek \\ Department of Child and Adolescent Studies, Utrecht University, The Netherlands
}

\begin{abstract}
Background: This study sought the answer to three questions: 1. Is having an intimate partner associated with the level of delinquency? 2. Does the quality of the relationship with an intimate partner, operationalised as partner support, predict the level of delinquency? 3. Does a relationship with an intimate partner or age moderate the association between parental support and delinquency? Method: Data from a three-wave, six-year longitudinal study of 1302 adolescents and young adults, aged 12-23 at wave 1, were used. Results: 1. Univariate latent growth curve analysis showed that, as predicted, having an intimate partner does not lead to less criminality among young adults over the age of 20. We found no support for the hypothesis among the group of 12- to 20-year-old adolescents, since the group of mid-adolescents who consistently have a partner is more criminal than the other groups. 2. Our findings show that partner support is negatively related to criminality in both $12-$ to 20-year-olds and 21- to 23-year-olds. The longitudinal effect of partner support is also uni-directional: partner support T1 certainly has an impact on criminality T3, but the reverse is not true. In both groups the influence of partner support is also greater than that of parental support. 3. Having an intimate partner moderates the association between parental support and delinquency, but in an agespecific manner. Parental support has no bearing on criminality when adolescents and young adults continuously have an intimate partner. Parental support does, however, cause a reduction in the level of criminality in adolescents and young adults who have never had a partner and adolescents who only have a partner at time 3. Conclusions: We interpret our results in terms of shifts in the relational system: if an adolescent finds a partner, that partner takes over the role of the parents in reducing criminality; if not, the parents remain important in doing so. Keywords: Partner relations, parentadolescent relations, delinquency, life-course model of delinquency, longitudinal studies.
\end{abstract}

Sampson and Laub published their life-course model of delinquency in 1990. This model postulates that criminality in adolescence and young adulthood is the result of the individual's propensity to criminal behaviour and of influences from the social environment. Sampson and Laub's model predicts both stability and change in criminality in the course of the person's life: stability because adolescents with a strong tendency towards criminal behaviour have a greater chance of continuing to be criminals in later life; change because adolescents with good social relationships with parents and peers have a greater chance of bringing their criminal behaviour to an end. With this theory Sampson and Laub questioned the hypothesis of Gottfredson and Hirschi (1990) who were convinced that the tendency to criminal behaviour was set down in the earliest years of childhood and could not be influenced by social relationships in later life. Since then, various studies have supported the Sampson and Laub model (Horney, Osgood, \& Haen-Marshall, 1995; Laub, Nagin, \& Sampson, 1998; Nagin, Farrington, \& Moffitt, 1995; Woodward, Fergusson, \& Horwood, 2001; Wright, Caspi, Moffitt, \& Silva, 1999). In this article we will try to take Sampson and Laub's insights one step further, and we shall consider the role that parents and intimate partners play in the development of criminal behaviour. For that purpose we shall discuss the data obtained from a number of longitudinal studies.

\section{Parents and delinquency}

A large number of these studies have shown that the quality of the youngster's relationship with his/her parents is a good predictor for the degree of criminal behaviour exhibited at a later stage. Little bonding with parents (Aseltine, 1995), inept parenting (Farrington, 1995; Simons, Chao, Conger, \& Elder, 2001), scant involvement and intimacy from the parents (Wright, Caspi, Moffitt, \& Silva, 1999, 2001), harsh and inconsistent parental discipline (Patterson, DeGarmo, \& Knutson, 2000; Patterson, Forgatch, Yoerger, \& Stoolmiller, 1998) lead to more criminality in the course of the adolescent's development. A few studies have shown that the prospective link between the quality of the parent-adolescent relationship and criminality is by nature gradual. The poorer the relationship with the parents is, and the more disciplinary, the greater the chance of persistent 
criminality (Patterson et al., 1998; StouthamerLoeber, Loeber, Wei, Farrington, \& Wikström, 2002). In addition, it has been demonstrated that the link between the quality of the parent-adolescent relationship and criminality is bi-directional: a poor relationship leads not only to a greater degree of criminality in later life, but criminality also leads to a deterioration of the parent-adolescent relationship as time progresses. This was found to be true for aversive and disciplinary parenting (Patterson et al., 2000; Vuchinich, Bank, \& Patterson, 1992), involvement and intimacy with parents (Wright et al., 1999, 2001) and parental support (Stice $\&$ Barrera, 1995).

\section{Intimate partner and delinquency}

A series of longitudinal studies have been carried out into the influence which an intimate partner has on the development of criminal behaviour. These studies have been particularly interested in the question of whether having an intimate partner or being married in itself leads to less criminality, or whether it is primarily the quality of the relationship with the intimate partner that makes an impact. Most studies show that having an intimate partner or a spouse does not affect delinquency. Sampson and Laub (1990) found that marriage had no influence on delinquency, and this result was reproduced by Laub et al. (1998). Moffitt, Caspi, Harrington, and Milne (2002) found no difference in prevalence of having an intimate partner between criminals and non-criminals and between adolescence-limited and life-course-persistent offenders, and Farrington (1995) and Nagin et al. (1995) reported no difference in prevalence as regards marriage between offenders and non-offenders at the age of 32 years. The results of existing research are, however, not entirely consistent. Farrington (1995) demonstrated that at the age of 22 being married did correspond with a lower level of delinquency. On the other hand, nearly all the studies show that the quality of the relationship with an intimate partner or spouse leads in time to less delinquency. Sampson and Laub (1990) and Nagin et al. (1998) reported that result for attachment to spouse, Quinton, Pickles, Maughan, and Rutter (1993) and Simons, Stewart, Gordon, Conger, and Elder (2002) for various measures of the quality of the relationship with a partner, and Wright et al. (1999) for intimacy and companionship with partner. In the study carried out by Simons et al., the impact of the quality of the partner relationship was only found for female subjects. One study, carried out by Giordano, Cernkovitch, and Rudolph (2002), found no such effect. But in their final statistical model Giordano et al. do report a $ß$ of -.21 between attachment to spouse time 1 and delinquency time 2, so that the lack of any significant effect might be explained by the low power of their sample.

The conclusion to be drawn from this overview is that it is not so much the having of an intimate partner or being married that leads to a decline in delinquency, but that the quality of the relationship with that intimate partner is the determining factor.

\section{Intimate partner as moderator of parental influence on delinquency?}

Five studies have investigated the extent to which the intimate partner and parents affect delinquency simultaneously. All these studies relate to young adults in the age group between 20 and 32, and the conclusion is unequivocal. Once young adults have an intimate partner, their parents no longer have any influence on their delinquency. Sampson and Laub (1993) reported that, in that case, parent-child relationships in mid-adolescence are not predictive for the level of delinquency in young adulthood. Laub et al. (1998) demonstrated that delinquency from the age of 20 could not be predicted from the attachment to parents, parental discipline and supervision during mid-adolescence. Woodward et al. (2002) reported that the level of physical discipline applied by the parents from childhood to mid-adolescence is not predictive for delinquency at age 21. Similarly, Giordano et al. (2002) found that attachment to parents and parental supervision during mid-adolescence was not predictive for delinquency at age 2728, and Nagin et al. (1995) showed that there were no differences in the quality of the relationship with parents for offenders and non-offenders at age 32. As we have shown above, these five studies quite consistently did find that the quality of the relationship with the intimate partner or spouse was predictive for delinquency. The conclusions drawn by the five studies stand in stark contrast to those of studies which only considered the association between the relationship with parents and delinquency, for these studies did indeed systematically report an association between the quality of the relationship with parents and delinquency. A possible explanation is that having an intimate partner might moderate the association between the relationship with parents and delinquency: the relationship with parents is predictive of the degree of criminality when youngsters have no intimate partners, but not predictive if they do have such a partner. Another explanation is that the moderation effect is an age-related effect. The studies which only examined the impact of the quality of the relationship with the parents related exclusively to adolescents between 12 and 20 years of age, and the studies which considered both the impact of the quality of the relationship with parents and that with the intimate partner related exclusively to young adults over the age of 20 . It is therefore possible that the influence of the parents diminishes as the adolescent grows older. In order to examine whether the diminished influence of the parents could be attributed to the existence of an intimate partner or to age alone, a design with at least four groups of subjects is required: adolescents 
with partner, adolescents without partner, young adults with partner and young adults without partner. Our study incorporates all four of these groups.

\section{Research questions}

For this study we used data from a three-wave, sixyear longitudinal study of 1302 adolescents and young adults, aged $12-23$ at wave 1 . This allows us to answer the following research questions.

1. Is having an intimate partner associated with the level of delinquency? To answer this question we will model univariate latent growth curves from age 12 to 29 for three groups: adolescents and young adults who have had systematic experience with an intimate partner (systematic partner experience group, from now on abbreviated to Spe), adolescents and young adults who have an intimate partner at wave 3 only (T3 partner group, T3p), and adolescents and young adults who have never had a partner (never partner group, $\mathrm{Np}$ ). We expect to find no differences in the level of delinquency between the three groups.

2. Does the quality of the relationship with an intimate partner, operationalised as partner support, predict the level of delinquency? We will study this question by using full recursive models. A new feature of our study is that we shall test this association for adolescents aged 12-20 and young adults aged 21-23 at time 1; up to now, studies on intimate partner and delinquency have been restricted to young adults aged 20 years and older. From our review of the earlier studies we derive the expectation that in the $21-23$ age group a good quality relationship with an intimate partner will reduce delinquency; in addition we will test this effect for the 12-20 age group.

3. Does a relationship with an intimate partner or age moderate the association between parental support and delinquency? We will study this question by testing in full recursive models crosssectional and across time associations between parental support and delinquency in the three partnership status groups, Spe, T3p and Np, and in the age groups $12-20$ and $21-23$. We expect to find that having an intimate partner or age will have a moderating effect.

\section{Method}

\section{Subjects}

Data for this study were collected as part of a broader multipurpose project, the 'Utrecht Study of Adolescent Development (USAD) 1991-1997' (Meeus \& 't Hart, 1993). In 1991 a national sample of 3392 Dutch adolescents aged 12 to 23 was drawn from an existing panel of 10,000 households. 'T Hart (1992) checked the representativeness of the first wave sample by comparing it with population figures published by the Dutch Central Statistical Office (CBS). No differences were found between the sample and the CBS figures with respect to district, urbanisation level, educational level and religious affiliation. The sample can therefore be regarded as representative of the Dutch indigenous adolescent population of the early 1990s. A random selection of 1300 subjects was targeted to be the sample for the longitudinal part of the study. Although the 3392 subjects of the first wave gave their informed consent to remain participants in the longitudinal study, 822 of them ultimately refused to take part in the second or third wave. So, the nonresponse rate between wave 1 and 3 was $24 \%$, and 1302 subjects were selected from the 2570 subjects eligible for the longitudinal study.

Analyses were carried out to test whether there were differences between the subjects that participated in the longitudinal sample and those who did not in terms of gender, age, educational level, and measures of parental and partner support and delinquency. Since $n$ was greater than 3000 in most of these analyses, significance level was set at $p<.01$. Logistic analyses showed that remaining in the longitudinal sample was associated with gender $(B=-.26, p<.01)$ and age $(B=.07, p<.01)$ and not with educational level (no contrast reaching $p<.01$ ). Fewer males and young adults stayed in the study than females and adolescents. Analyses of variance showed no differences between participants in the longitudinal study and nonparticipants in terms of parental support at wave 1 : $F(1,3003)=4.48, p>.01$, partner support at wave 1 , $F(1,1345)=.02, p>.05$, and youth delinquency at wave 1: $F(1,3390)=2.38, p>.05$. Additionally, we checked whether the associations between parental and partner support and delinquency were different for those who stayed in the study and those who pulled out. The correlations between parental support and delinquency were -.09 and -.10 respectively for participants and non-participants, while those between partner support and delinquency were -.20 and -.15 respectively. In both cases the correlations of participants and non-participants did not differ significantly ( $p$ 's $>.05)$. Although the results of this study must be interpreted with caution, the findings concerning delinquency and parental and partner support can be generalised to broader populations.

The sample consisted of 550 males (42\%) and 752 females $(58 \%)$. The respondents were evenly distributed over the four age categories (based on age at first wave): 321 early adolescents (25\%), 341 middle adolescents (26\%), 261 late adolescents (20\%), and 379 young adults (29\%). Further, the educational level of the respondents could be differentiated as 54\% low-middle, and $46 \%$ high. About $48 \%$ of all respondents had a religious affiliation, while $52 \%$ had none. In total, $99 \%$ of the sample consisted of adolescents who were of Dutch origin, while $1 \%$ came from a different ethnic background.

\section{Procedure}

The respondents were interviewed in their homes. They were also asked to complete an extensive questionnaire in the presence of the interviewer. They were then given 
another questionnaire to fill out on their own within a week and send back to the research organisation. All 1302 participants returned this second questionnaire in the three waves.

\section{Measures}

Parental support was assessed by means of a list of six questionnaire items. Respondents were asked to indicate on a 10-point scale (range 10-100) the degree of social support they received in the domain of personal relationships, leisure time and school/work from their father and mother. Cronbach's alphas for parental support were $.87, .88$, and .87 at wave 1 , wave 2 and wave 3 respectively. Concurrent validity of the parental support measure has been demonstrated by correlations ranging from .45 to .56 between the scales of parental support and the parental attachment scale of the Inventory of Parent and Peer Attachment by Armsden and Greenberg (1987) (Helsen, Vollebergh, \& Meeus, 1999).

Partner support was assessed by means of a list of three questionnaire items. Respondents indicated on a 10-point scale (range 10-100) the degree of social support they received in the domain of personal relationships, leisure time and school/work from their intimate partner. Cronbach's alphas for parther support were $.82, .75$, and .74 at wave 1 , wave 2 and wave 3 respectively.

Delinquency was assessed in the oral interview as the number of delinquent acts the respondents reported over the past 12 months. The delinquency measure consists of 21 items pertaining to 3 types of delinquent behaviour: violent crime (e.g., 'Have you ever wounded anybody with a knife or other weapon?'), vandalism (e.g., 'Have you ever covered walls, buses, or entryways with graffiti?'), and crime against property (e.g. 'Have you ever bought something which you knew was stolen?'). Subjects indicated whether they had behaved in one of these ways during the past 12 months on a 2 -point scale $(0=$ no, $1=$ yes $)$. The scores on the 21 items were summed with ranges $0-10$ in wave $1,0-9$ in wave 2 , and $0-6$ in wave 3 ; mean scores were $.81, .70$ and .48 respectively. In the structural equation models standardised scores were used. Latent class analysis of wave 1 data showed the delinquency measure to be onedimensional (van der Heijden, 't Hart, \& Dessens, 1997). The validity of the delinquency measure has been amply demonstrated in Dutch research (JungerTas \& Kruissink, 1990).

Partnership status was assessed by one item asking whether the respondent had had a relationship with an intimate partner lasting at least three months. Twelve hundred and forty-five of the 1302 respondents had a valid score on this measure in all three waves. The yesno answers to this question across the three waves could be categorised in four patterns. 1. Systematic partner experience group (Spe): respondents who have had an intimate partner in all three waves or in waves 1 and 3 , and consequently had experience with one or more partners for a period that spanned, although not necessarily continuously, a period of 6 years. 2. T3 partner group: respondents who moved from having no partner in wave 1 to having a partner in wave 3. 3. Never partner group: respondents who never had a partner.
Table 1 Partnership status by age

\begin{tabular}{lcccc}
\hline & \multicolumn{4}{c}{ Partnership status } \\
\cline { 2 - 5 } & $\begin{array}{c}\text { Systematic } \\
\text { partner } \\
\text { experience }\end{array}$ & $\begin{array}{c}\text { T3 } \\
\text { partner }\end{array}$ & $\begin{array}{c}\text { Never } \\
\text { partner }\end{array}$ & $\begin{array}{c}\text { No } \\
\text { pattern }\end{array}$ \\
\hline Adolescents, aged & $12-20$ & & & \\
$12-14$ & 16 & 107 & 162 & 28 \\
$15-17$ & 53 & 120 & 124 & 36 \\
$18-20$ & 100 & 67 & 66 & 13 \\
Total & 169 & 294 & 352 & 77 \\
Young adults, aged 21-23 & & & \\
$21-23$ & 250 & 41 & 55 & 7 \\
Grand total & 419 & 335 & 407 & 84 \\
\hline
\end{tabular}

4. No pattern group: respondents who did not have a partner in wave 3 and had a partner in one or two of the other waves. Table 1 gives the numbers for each of these groups.

In the age-related analyses we used two age categories within these groups: adolescents aged 12-20 in wave 1 , and young adults aged $21-23$ in wave 1 . The nopattern group will be left out of the analyses, since it is not possible to designate this group as a group with partner, moving into partnership, or without partner. Leaving out this group $(n=84)$ and cases with missing values reduced the sample size to 1121 .

\section{Results \\ Does the relationship with an intimate partner reduce the level of delinquency?}

Latent growth curves were estimated to test our hypothesis that having a relationship with an intimate partner as such does not affect the level of delinquency. Two-factor latent growth models of delinquency were estimated. ${ }^{1}$ Using these growth curves we tested whether the rate of change (slope) was significantly different from zero and had a curvilinear shape. We estimated the univariate latent growth curves separately for the systematic partner experience group, the time 3 partner group, and the never partner group.

The latent growth curve models for delinquency with 6 successive ages showed a respectable fit with the data in all three groups (CFIs were at least .94 and RMSEAs .06 or lower). Thus in all three models the curvilinear form of the slopes for changes in delinquency was shown to have a good fit, with delinquency peaking at the ages 15-17. Figure 1 presents the latent growth curves for the three groups.

To find out whether having a relationship with an intimate partner reduces the level of delinquency we tested whether the initial levels, the rate of change and the peak at ages 15-17 of the three groups differ. Findings showed that the three groups are not ${ }^{1}$ Details of the growth curve analyses can be obtained from the
corresponding author. 


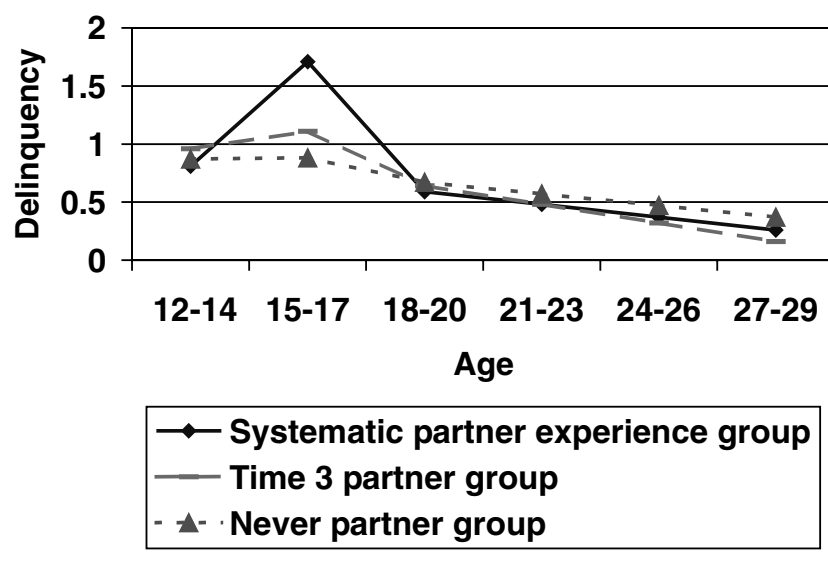

Figure 1 Development of delinquency from ages 12-29 in the systematic partner experience group, the time 3 partner group and the never partner group

different in their initial level or in their mean increase or decrease of delinquency, but that at ages 15-17 the increase of delinquency was stronger in the Spe group than in the T3p $\left(\Delta \chi^{2}=10.10, \Delta d f=1\right.$, $p<.001)$ and the $\mathrm{Np}$ group $\left(\Delta \chi^{2}=19.10, \Delta d f=1\right.$, $p<.001)$. Additional analyses showed that in all three groups the level of delinquency of males was higher than that of females, that the mean increase or decrease was the same for males and females, and that the increase of delinquency at ages 15-17 was strongest in the Spe group for both males and females. The growth curves of the three groups were the same for high- and low-educated subjects. These findings support and expand on those of earlier studies. Having an intimate partner in itself does not reduce the level of delinquency from age 20 to ages 27-29. The findings for ages 15-17 are new: having a partner in mid-adolescence goes hand in hand with an elevated level of delinquency.

\section{Does quality of relationship with intimate partner predict delinquency, and does relationship with intimate partner moderate the association between parental support and delinquency?}

Strategy of analyses. To answer these questions we used data from waves 1 and 3, and specified a series of six-year longitudinal models. Since we were not only interested in the effects of partnership status, but also in age differences in these effects, we tested the model that fitted best for the total group in several multigroup analyses in AMOS. Using a six-group multigroup model, Spe/12-20, Spe/21-23, T3p/ 12-20, T3p/21-23, Np/12-20 and Np/21-23, we tested whether the model differed for: 1 . the three partnership groups, 2 . the two age groups, and 3 . the six combined partnership status by age groups. Figures $2 a-2 c$ show the models for the different groups. For reasons of presentation we show one figure for each partnership status group; nested within each partnership status group are the two age groups.
The figures show that the models of Spe groups, the T3p groups and the Np groups contain different sets of parameters. This is no problem, since AMOS allows multigroup analyses to be carried out on groups that have different sets of parameters. The covariance matrices of the six groups were used as input for the structural equation models. For these multigroup analyses we compared two models: a restricted model, in which all the estimated parameters were required to be equal across groups, and a non-restricted model in which these parameters were allowed to differ across groups: T1 correlations between the support variables and delinquency and between parental and partner support, cross-lagged paths from the support variables $\mathrm{T} 1$ to delinquency $\mathrm{T} 3$, and from delinquency $\mathrm{T} 1$ to the support variables $\mathrm{T} 3$, and cross-lagged paths from parental support T1 to partner support $\mathrm{T} 3$, and from partner support $\mathrm{T} 1$ and parental support T3. The models were compared by subtracting their chi-squares. The chi-square difference test was used to determine which model best represents the data. Table 2 presents these model comparisons. In all models we included gender and educational level as control variables.

The table shows that the models 'partnership status groups different', 'age groups different' and 'partnership status by age groups different' did not provide a significantly better fit than the restricted model (respectively $\Delta \chi^{2}=12.53, \Delta d f=3, p>.05$; $\Delta \chi^{2}=6.91, \Delta d f=6, p>.05 ; \Delta \chi^{2}=22.29, \Delta d f=15$, $p>$.05). This means that the model parameters are not systematically different for age groups (Spe/1220 and Spe/21-23 groups, T3p/12-20 and T3p/2123 groups, and $\mathrm{Np} / 12-20$ and $\mathrm{Np} / 21-23$ groups), partnership status groups (Spe/12-20, T3p/12-20 and $\mathrm{Np} / 12-20$ groups and Spe/21-23, T3p/21-23 and $\mathrm{Np} / 21-23$ groups), nor all the six partnership status by age groups. Consequently, it makes sense to look for specific partnership by age effects. Therefore we then specified a multigroup model where some parameters were allowed to vary across the six groups, and some were not: 'partnership status by age groups partially different'. The following assumptions, partly based on our literature review, and partly explorative by nature, guided the model specification: 1 . In both Spe groups there will be the same association between partner support $\mathrm{T} 1$ and delinquency $\mathrm{T} 1$, and partner support $\mathrm{T} 1$ will be predictive of delinquency T3. We based this assumption on our review of studies among young adults and expected to find the same results among adolescents. 2 . In both Spe groups and in the oldest T3p group there will be no association between parental support $\mathrm{T} 1$ and delinquency $\mathrm{T} 1$, parental support T1 and delinquency T3, and delinquency T1 and parental support T3. For both age groups within the Spe group we again based this assumption on our review of studies among young adults and expected to find the same results among adolescents. In addition, we specified that young adults in 

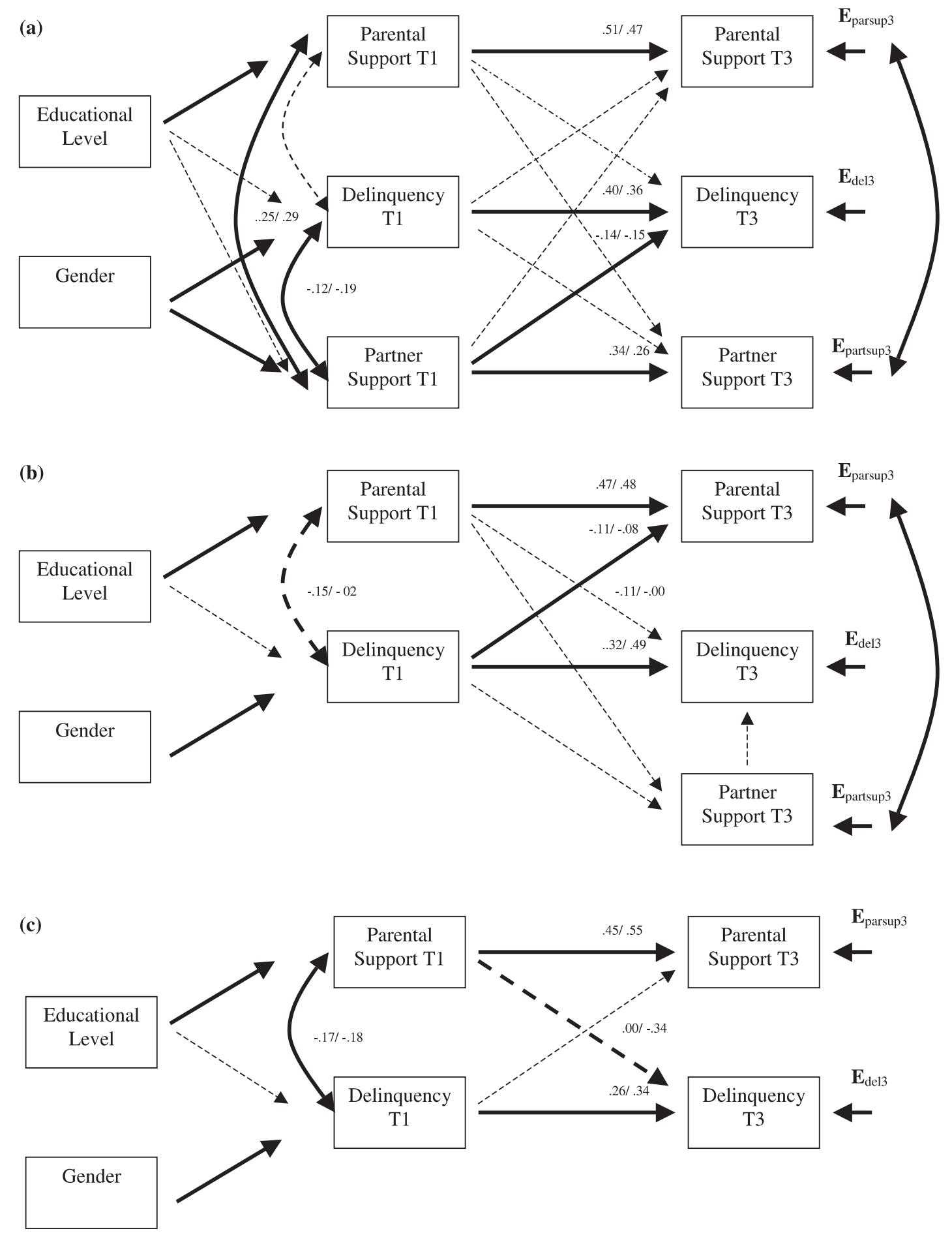

Figure 2 Models for the six-year partner groups (a), the time 3 partner groups (b) and the never partner groups (c). Statistics of the relevant significant parameters of both age groups within the partnership status groups are printed. The first statistic is that of the youngest group, the second that of the oldest group

- Significant correlations or paths in both age groups

_ _ - Significant correlations or paths in one age group

- . - - - - Non significant correlations or paths in both age groups

the T3p group would show the same pattern with regard to the association between parental support and delinquency as the Spe groups. So, we assumed that for young adults moving into a relationship with an intimate partner, parental support - as in the Spe groups - is no longer important in reducing delinquency. 3. For both Np groups and the youngest T3p group we specified associations between parental support $\mathrm{T} 1$ and delinquency $\mathrm{T} 1$, parental support $\mathrm{T} 1$ and delinquency $\mathrm{T} 1$, and delinquency $\mathrm{T} 1$ and parental support T3. Here we assumed that for adolescents and young adults who have never had a partner, as well as for adolescents that do not have an intimate partner yet, parents stay important in 
Table 2 Model comparisons

\begin{tabular}{|c|c|c|c|c|c|}
\hline \multirow[b]{2}{*}{ Model } & \multicolumn{5}{|c|}{ Model comparison tests } \\
\hline & $\chi^{2}$ & df & $\Delta \chi^{2}$ & $\Delta \mathrm{df}$ & $p(\mathrm{~d})$ \\
\hline All groups similar & 250.99 & 108 & & & \\
\hline Partnership status groups different & 238.46 & 102 & 12.53 & 6 & $p>.05$ \\
\hline Age groups different & 244.08 & 105 & 6.91 & 3 & $p>.05$ \\
\hline Partnership status by age groups different & 228.70 & 93 & 22.29 & 15 & $p>.05$ \\
\hline Partnership status by age groups partially different & 231.54 & 104 & 19.45 & 4 & $p<.05$ \\
\hline
\end{tabular}

Table 3 Standardised maximum-likelihood estimates and fit coefficients of model partnership status by age group partially different

\begin{tabular}{|c|c|c|c|c|c|c|}
\hline \multirow[b]{3}{*}{ Parameter } & \multicolumn{6}{|c|}{ Age group by partnership status group } \\
\hline & \multicolumn{3}{|c|}{$12-20$} & \multicolumn{3}{|c|}{$21-23$} \\
\hline & $\begin{array}{c}\text { Spe } \\
n=164\end{array}$ & $\begin{array}{c}\text { T3p } \\
n=291\end{array}$ & $\begin{array}{c}\mathrm{Np} \\
n=346\end{array}$ & $\begin{array}{c}\text { Spe } \\
n=225\end{array}$ & $\begin{array}{c}\text { T3p } \\
n=41\end{array}$ & $\begin{array}{c}\mathrm{Np} \\
n=54\end{array}$ \\
\hline \multicolumn{7}{|l|}{ Exogenous variables-T1 variables } \\
\hline Educational level-Delinquency T1 & -.03 & -.03 & -.03 & -.04 & -.05 & -.04 \\
\hline Educational level-Parental support T1 & $-.09 * * *$ & $-.10^{* * *}$ & $-.11^{* * *}$ & $-.09 * * *$ & $-.11^{* * *}$ & $-.09 * * *$ \\
\hline Educational level-Partner support T1 & -.07 & & & -.09 & & \\
\hline Gender-Delinquency T1 & $-.21^{* * *}$ & & & $-.29 * * *$ & & \\
\hline Gender-Parental support T1 & $.08^{* *}$ & $-.21^{* * *}$ & $-.22^{* * *}$ & $.07 * *$ & $-.28^{* * *}$ & $-.29 * * *$ \\
\hline Gender-Partner support T1 & $.20^{* * *}$ & $.08 * *$ & $.08^{* *}$ & $.23^{* * *}$ & $.08 * *$ & $.07^{* *}$ \\
\hline \multicolumn{7}{|l|}{ T1 correlations } \\
\hline Parental support T1-Delinquency T1 & -.01 & $-.15^{* * *}$ & $-.17^{* * *}$ & .01 & -.02 & $-.18^{* *}$ \\
\hline Parental support T1- Partner support T1 & $.25^{* * *}$ & & & $.29 * * *$ & & \\
\hline Partner support T1-Delinquency T1 & $-.12^{* * *}$ & & & $-.19 * * *$ & & \\
\hline \multicolumn{7}{|l|}{ T3 path } \\
\hline Partner support T3-Delinquency T3 & & -.01 & & & -.04 & \\
\hline \multicolumn{7}{|l|}{ Stability paths } \\
\hline Parental support T1-T3 & $.51^{* * *}$ & $.47^{* * *}$ & $.45^{* * *}$ & $.47^{* * *}$ & $.48^{* * *}$ & $.55^{* * *}$ \\
\hline Delinquency T1-T3 & $.40^{* * *}$ & $.32^{* * *}$ & $.26^{* * *}$ & $.36^{* * *}$ & $.49^{* * *}$ & $.34 * * *$ \\
\hline Partner support T1-T3 & $.34^{* * *}$ & & & $.26^{* * *}$ & & \\
\hline \multicolumn{7}{|l|}{ Cross-lagged paths } \\
\hline Parental support T1-Delinquency T3 & .00 & $-.11^{*}$ & .00 & .00 & .00 & $-.34^{* *}$ \\
\hline Delinquency T1-Parental support T3 & .00 & $-.11^{*}$ & .00 & .00 & $-.08^{*}$ & .00 \\
\hline Partner support T1-Delinquency T3 & $-.14^{* *}$ & & & $-.15^{* *}$ & & \\
\hline Delinquency T1-Partner support T3 & -.04 & -.04 & & -.02 & -.02 & \\
\hline Parental support T1-Partner support T3 & 04 & .04 & & .03 & .04 & \\
\hline Partner support T1-Parental support T3 & 08 & & & .06 & & \\
\hline \multicolumn{7}{|l|}{ Fit coefficients } \\
\hline$\chi^{2}$ & 231.54 & & & & & \\
\hline df & 104 & & & & & \\
\hline GFI & .95 & & & & & \\
\hline RMSEA & .03 & & & & & \\
\hline
\end{tabular}

Note: Due to missing values the $n$ 's in the different groups are slightly different from those in Table 1 .

${ }^{*} p<.05 ;{ }^{* *} p<.01 ;{ }^{* * *} p<.001$.

reducing delinquency. In total, the model specified for 18 parameters in the Spe groups whether they were different or not, for 12 parameters in the T3p groups, and for 9 parameters in the $\mathrm{Np}$ groups. Inspection of the model parameters for the six groups and the modification indices suggested a different specification for only 4 of the total of 39 paths, which was done consecutively. The resulting model fitted the data better than the restricted model $\left(\Delta \chi^{2}=231.54, \Delta d f=4, p<.001\right)$. According to the conventions for good fit of GFI > 90 (Jöreskog \& Sörbom, 1989) and RMSEA between .03 and .07 (Steiger, 1990), the fit of the model was satisfactory, with fit indices: GFI $=.95$, RMSEA $=.03$. In sum it can be concluded that some of the parameters are different for all groups, while others are different for some or none of the groups. The results for each of the groups are shown in Figures $2 \mathrm{a}-2 \mathrm{c}$ and in Table 3.

The figures and table show consistent associations across groups between educational level and gender and the support variables and delinquency. Adolescents and young adults with a high educational level receive somewhat more parental support, and girls receive more parental and partner support and are less delinquent as compared to boys. 


\section{Does partner support predict delinquency and does it override parental support in the six-year partner group?}

We tested whether in the Spe groups 1. partner support would predict delinquency, and 2. parental support would be associated to delinquency, see Figure 2a and Table 3, columns Spe. The figure and table show that there are no substantial differences between the Spe/12-20 and Spe/21-23 groups, so the findings are not age-specific. A higher level of partner support at $\mathrm{T} 1$ goes hand in hand with less delinquency at $\mathrm{T} 1$, while no association between parental support T1 and delinquency T1 was found. The stability of parental support T1-T3 was high, while moderate levels of stability for partner support T1-T3 and delinquency T1-T3 were found. One cross-lagged effect was found to be significant: a higher level of partner support at T1 predicted a lower level of delinquency at T3. Taken together, these findings show that a higher level of partner support is accompanied by a lower level of delinquency across time, that the earlier level of partner support reduces the later level of delinquency, and that parental support is not associated to delinquency in this group. This pattern of findings supports our assumption for the link between partner support and delinquency in young adults, as well as adolescents.

\section{Does relationship with intimate partner moderate the correlation between parental support and delinquency?}

The analyses of the Spe group showed partner support to override parental support in reducing delinquency. Is the opposite also true: does parental support predict delinquency if there is no intimate partner? And, if so, does this vary with age? Figure $2 \mathrm{c}$ and Table 3 show quite consistently that parental support does indeed predict delinquency in adolescents and young adults who do not have an intimate partner. In the younger and older Np groups negative T1 correlations between parental support and delinquency were found (-.17 and -.18), and in the oldest $\mathrm{Np}$ group parental support $\mathrm{T} 1$ was found to reduce delinquency at T3 (-.34). So, in adolescents and young adults who have never had a partner, parental support remains important in predicting the level of delinquency. The findings show this to be more clearly the case for the older than the younger age group. The findings for the $\mathrm{T} 3 \mathrm{p}$ group fit quite well in into this picture, see Figure $2 \mathrm{~b}$ and Table 3 . In the younger T3p group negative associations were found between parental support T1 and delinquency $\mathrm{T} 1(-.15)$ and parental support $\mathrm{T} 1$ and delinquency T3 (-.11), while in the older group these associations disappear (-.02 and .00). This again looks to be an age-related phenomenon. Adolescents who are on their way to finding an intimate partner are still influenced by parental support, while for young adults such parental influence wanes. These agerelated findings show that the difference in the impact of parental support is greater between the older $\mathrm{Np}$ and T3p groups than between the younger $\mathrm{Np}$ and T3p groups. We point to two additional findings. In both the $\mathrm{T} 3 \mathrm{p}$ groups a negative relation between delinquency T1 and parental support T3 was found (-.11 and -.08). These findings show that delinquency can be an obstacle for maintaining good relationships with parents.

In sum, we conclude that our findings are systematically in favour of the moderating role of the relationship with an intimate partner. In adolescents and young adults who have an intimate partner, partners are, but parents are not, important in reducing delinquency, while in adolescents and young adults who have never had an intimate partner parents are important. Parental support is still important for adolescents who are on track towards moving into a relationship with an intimate partner, while the impact of parental support wanes for young adults in the T3p group. The findings are not age-related as far as the impact of partner support is concerned.

\section{Discussion}

The data from this study support the life-course model developed by Sampson and Laub (1990). Criminal behaviour evinces a reasonable degree of stability but is also influenced by the social environment, in this case parental and partner support. The most important contribution of this article is that it shows that the significance of support by partner and parents varies for the various groups of adolescents and young adults.

\section{Intimate partnership, partner support and delinquency}

Our first hypothesis was that having an intimate partner does not lead to less criminality. This hypothesis was confirmed for young adults over 20 years of age; in this group there is no difference in the degree of criminality between those who consistently have an intimate partner (Spe), those who have never had an intimate partner (Np) and those who only have an intimate partner at a relatively later age (T3p). In that respect our investigation replicates the results found in the earlier studies carried out by Farrington (1995), Laub et al. (1998), Moffitt et al. (2002), Sampson and Laub (1990) and Nagin et al. (1995). We found no support for the hypothesis among the group of 12- to 20-year-old adolescents, since the group of mid-adolescents who consistently have a partner is more criminal than the other groups. This result shows that having an intimate partner can have age-specific effects on criminality. 
By late adolescence and young adulthood, the fact of having a partner no longer results in either more or less criminality, but in mid-adolescence it does result in increased criminality. A second outcome of our study is that the quality of the relationship with an intimate partner, operationalised as partner support, has a stronger impact on the criminality of young adults than the fact of having an intimate partner. As far as that is concerned, our results replicated the findings of earlier studies carried out by Sampson and Laub (1990) and others.

Our findings show convincingly that partner support is negatively related to delinquency. In both the 12-20 and the 21-23 age groups of adolescents and young adults with a six-year partner relationship, the degree of partner support was found to lead to less delinquency. The longitudinal effect of partner support is also uni-directional: partner support T1 certainly has an impact on delinquency T3, but the reverse is not true. In both groups the influence of partner support is also greater than that of parental support, and parental support is not associated at all with delinquency.

\section{Intimate partnership as moderator of parental support}

Having an intimate partner moderates the correlation between parental support and delinquency, but in an age-specific manner. Parental support has no bearing on criminality when adolescents and young adults continuously have an intimate partner, as evidenced by the data for the Spe group. A recent study by Overbeek, Vollebergh, Engels, and Meeus (2003) reports a comparable finding: in late adolescents with an intimate partner no association between parental attachment and emotional problems was found. Parental support does, however, lead to a reduction of criminality in adolescents and young adults who have never had a partner $(\mathrm{Np})$ or only at time 3 (T3p). Nonetheless, the association between parental support and criminality in the Np and T3p group does vary with age. In both these age categories within the $\mathrm{Np}$ group there is a negative association between parental support and delinquency at time 1 , and in the oldest age group there is a substantial and uni-directional negative impact of parental support T1 on delinquency T3. The influence of parental support on criminality is thus manifestly stronger in the oldest age group within the Np group. Within the T3p group there is also a clear association between parental support and delinquency, but this only applies to the youngest age category and, consequently, this effect is once more age specific. In the youngest group there is a negative correlation between the degree of parental support and criminality at time $\mathrm{T} 1$, and a higher degree of parental support at time T1 is also predictive of less criminality at time T3.

\section{Shifts in the relational system}

Our results suggested a developmental pattern regarding the significance of parents and an intimate partner in reducing delinquency. As soon as adolescents and young adults become involved in a steady relationship with an intimate partner, as in the Spe group, their relational system changes. The relationship with an intimate partner becomes the most important one, taking over dominance from the parents, and the quality of the relationship with the intimate partner becomes the most influential factor in counteracting criminal behaviour. This change in the relational system does not occur in the case of adolescents and young adults who have never had an intimate partner, and parents remain the most important factor. The association between parental support and delinquency is stronger in the older $\mathrm{Np}$ group in comparison with the younger Np group. The correlation between parental support T1 and delinquency $\mathrm{T} 1$ in the younger group is -.17 , and the path parental support T1-delinquency T3 is .00, while in the older group these same values are -.18 and -.34 . This illustrates that parental support in both groups is related to the level of delinquency, and also that the significance of parental support increases as it becomes more evident that there is no chance of a relationship with an intimate partner. The dominance of the parents in the relational system of the young adults is then reaffirmed as it were, and support by the parents becomes more important in curbing criminality. For adolescents in the Np group it is less clear that there is no chance for a relationship with an intimate partner, the dominance of the parents in the relational system has not yet been reaffirmed, and the significance of parental support on curbing criminal behaviour is much smaller. The development of the relational system in the T3p group vacillates between that of the Np group and that of the Spe group. As far as the adolescents in the T3p group are concerned, parental support is related to criminality, but in the case of the young adults in the T3p group this support no longer has any impact on the level of criminality. The correlation between parental support $\mathrm{T} 1$ and delinquency $\mathrm{T} 1$ in the younger group is -.15 , the path parental support T1-delinquency T3 is -.11 and the path delinquency T1-parental support T3 is -.11, while in the older group the corresponding values are $-.02, .00$ and -.08 . Age is therefore an independent factor in the T3p group. We interpret this as an agespecific process of separation. Young adults become independent from their parents and the parents are therefore no longer an important factor in reducing delinquency. This separation process has not yet occurred in the case of adolescents, and the parents retain some influence. This explanation in terms of separation from the parents is supported by earlier investigations which have shown that the correlation between parental support and emotional problems decreases as adolescents become older (Helsen, 
Vollebergh, \& Meeus, 2000). Summing up, therefore, we can draw three conclusions. 1. If adolescents and young adults have an ongoing relationship with an intimate partner, that partner takes over the role of the parents in the curbing of delinquency. 2. If youngsters have no chance to find such a partner, the influence of the parents increases as the subject gets older. 3. The transition to a partner relationship has not yet been made in the T3p group, but it cannot be ruled out that this may yet occur. In that case, the influence of the parents will decrease as the age of the subject increases.

We have interpreted our results in terms of changes in the relational system of adolescents and young adults. But this does not imply that personal relationships are not important for the prevention of criminality. If anything, our results show that lasting good personal relationships with parents or partner lead to less criminal behaviour. As such, our results are in accordance with Hirschi's social control theory (1969) and social psychological theories about investment in close relationships (Rusbult, 1983; Bui, Peplau, \& Hill, 1996). It seems to us that the level of investment in personal relationships is crucial to our understanding of the association between peer relationships and criminality. Our results showed that investment in a personal relationship by a peer, the intimate partner, leads to less criminality, while many other studies have shown that having deviant friends goes hand in hand with increased criminality (Patterson, Reid, \& Dishion, 1992; Simons et al., 2001). This suggests that relationships with deviant friends lead to increased criminality because youngsters share the standards and values of these friends in regard to the permissibility of criminal behaviour, but also because such relationships are impersonal (Bukowski, Sippola, \& Newcomb, 2000; Luthar \& McMahon, 1996).

\section{Issues and limitations}

We discuss a number of suggestions for further investigation and some of the limitations of this particular study. Firstly, when interpreting the results, it is important to bear in mind that all the concepts used in the present study were assessed by the self-report method. This means that when we refer, for instance, to parental support and delinquency, we are speaking of the adolescents' perception of the support offered by parents and self-observed delinquency.

Common method variance, the tendency of subjects to respond to different questions in the same way, is a threat to the validity of self-reports. For two reasons, however, we think it to be quite unlikely that our results could be explained by common method variance. 1 . The data about parental and partner support were extracted from a written questionnaire while the data about criminality were taken from oral interviews which were held about one week before the questionnaires were filled out. So, the data on sup- port and delinquency were collected at different time points using different data collection strategies. 2 . The main findings of our study are that the associations between the support variables and delinquency are different for the six groups we distinguished. It is almost impossible to explain these findings in terms of common method variance. Such an explanation would have to assume that common method variance takes effect differently in the six groups. We think it quite unlikely for such a common method variance by group interaction to occur.

A limitation of our study is that we nearly always found effects with a small effect size (Cohen, 1992). On the other hand, it should be noted that the cross-lagged effects between the support variables and delinquency we have found were estimated for a period of 6 years, and that these effects as a rule had the same effects size as the T1 correlations between the support variables and delinquency. We take this as a strong indication that these longitudinal effects are meaningful. In this connection, we concur with the observation of Prentice and Miller (1992) that small effects can be impressive if they are of theoretical importance.

\section{Acknowledgement}

This research was supported by grants from the Dutch Organisation for Scientific Research (NWO) to the Utrecht Study on Adolescent Development (USAD) 1991-1997.

\section{Correspondence to}

Wim Meeus, Department of Child and Adolescent Studies, Post box 80.140, 3508 TC Utrecht, The Netherlands. Email: W.H.J.Meeus@fss.uu.nl

\section{References}

Armsden, G., \& Greenberg, M. (1987). The inventory of parent and peer attachment: Individual differences and their relationship to psychological well-being in adolescence. Journal of Youth and Adolescence, 16, 427-453.

Aseltine, R.H. (1995). A reconsideration of parental and peer influences on adolescent deviance. Journal of Health and Social Behavior, 36, 103-121.

Bui, K.T., Peplau, L.A., \& Hill, C.T. (1996). Testing the Rusbult model of relationship commitment and stability in a 15-year study of heterosexual couples. Personality and Social Psychology Bulletin, 22, 12441257.

Bukowski, W.M., Sippola, L.K., \& Newcomb, A.F. (2000). Variations in patterns of attraction to sameand other-sex peers during early adolescence. Developmental Psychology, 36, 147-154.

Cohen, J. (1992). A power primer. Psychological Bulletin, 112, 155-159.

Farrington, D. (1995). The development of offending and antisocial behaviour from childhood: Key findings from the Cambridge Study in delinquent development. Journal of Child Psychology and Psychiatry, 36, 929-964. 
Giordano, P.C., Cernkovich, S.A., \& Rudolph, J.L. (2002). Gender, crime, and desistance: Toward a theory of cognitive transformation. American Journal of Sociology, 107, 990-1064.

Gottfredson, M., \& Hirschi, T. (1990). A general theory of crime. Stanford, CA: Stanford University Press.

Hart, H. 't. (1992). Opzet en uitvoering van het WILpanel 1 en 2 [Design and data-collection of The Utrecht Study of Adolescent Development 1 and 2]. Unpublished manuscript, Utrecht University.

Helsen, M., Vollebergh, W., \& Meeus, W. (1999). Psychosociale problemen in de adolescentie: de samenhang met hechting aan ouders en vrienden en identiteit [Psychosocial problems in adolescence: Associations with parental and peer attachment and identity]. Nederlands Tijdschrift voor de Psychologie, 54, 256-275.

Helsen, M., Vollebergh, W., \& Meeus, W. (2000). Social support from parents and friends and psychosocial problems in adolescence. Journal of Youth and Adolescence, 29, 319-335.

Hirschi, T. (1969). Causes of delinquency. Berkeley, CA: University of Berkeley Press.

Horney, J., Osgood, D.W., \& Marshall, I.H. (1995). Criminal careers in the short term: Intra-individual variability in crime and its relation to local life circumstances. American Sociological Review, 60, 655-673.

Jöreskog, K.G., \& Sörbom, D. (1989). Lisrel 7: A guide to the program and applications. Chicago: SPSS.

Junger-Tas, J., \& Kruissink, M. (1990). Ontwikkeling van de jeugdcriminaliteit: Periode 1980-1988 [Trends in youth delinquency: Period 1980-1988]. Arnhem: Gouda Quint.

Laub, J.H., Nagin, D.S., \& Sampson, R.J. (1998). Trajectories of change in criminal offending: Good marriages and the desistance process. American Sociological Review, 63, 225-238.

Luthar, S.S., \& McMahon, T.J. (1996). Peer reputation among inner-city adolescents: Structure and correlates. Journal of Research on Adolescence, 6, 581-603.

Meeus, W., \& 't Hart, H. (1993). Jongeren in Nederland [Young people in the Netherlands]. Amersfoort: Academische Uitgeverij.

Moffitt, T.E., Caspi, A., Harrington, H., \& Milne, B.J. (2002). Males on the life-course-persistent and adolescence-limited antisocial pathways: Follow-up at age 26 years. Development and Psychopathology, 14, 179-207.

Nagin, D.S., Farrington, D.P., \& Moffitt, T.E. (1995). Life-course trajectories of different types of offenders. Criminology, 33, 111-139.

Overbeek, G., Vollebergh, W., Engels, R.C.M.E., \& Meeus, W. (2003). Parental attachment and romantic relationships: Associations with emotional disturbance during late adolescence. Journal of Counseling Psychology, 50, 28-39.

Patterson, G.R., DeGarmo, D.S., \& Knutson, N. (2000). Hyperactive and antisocial behaviors: Comorbid or two points in the same process? Development and Psychopathology, 12, 91-106.

Patterson, G.R., Forgatch, M.S., Yoerger, K.L., \& Stoollmiller, M. (1998). Variables that initiate and maintain an early-onset trajectory for juvenile offending. Development and Psychopathology, 10, 531-547.
Patterson, G.R., Reid, J.B., \& Dishion, T.J. (1992). A social interactional approach: Vol 4. Antisocial boys. Eugene, OR: Castalia.

Prentice, D., \& Miller, D. (1992). When small effects are impressive. Psychological Bulletin, 112, 160-164.

Quinton, D., Pickles, A., Maughan, B., \& Rutter, M. (1993). Partners, peers, and pathways: Assortive pairing and continuities in conduct disorder. Development and Psychopathology, 5, 763-783.

Rusbult, C.E. (1983). A longitudinal test of the investment model: The development (and deterioration) of satisfaction and commitment in heterosexual involvements. Journal of Personality and Social Psychology, 45, 101-117.

Sampson, R.J., \& Laub, J.H. (1990). Crime and deviance over the life course: The salience of adult social bonds. American Sociological Review, 55, 609-627.

Sampson, R.J., \& Laub, J.H. (1993). Crime in the making: Pathways and turning points through life. Cambridge, MA: Harvard University Press.

Simons, R.L., Chao, W., Conger, R.D., \& Elder, G.H. (2001). Quality of parenting as mediator of the effect of childhood defiance on adolescent friendship choices and delinquency: A growth curve analysis. Journal of Marriage and Family, 63, 63-79.

Simons, R.L., Stewart, E., Gordon, L.C., Conger, R.D., \& Elder, G.E. (2002). A test of life-course explanations for stability and change in antisocial behavior from adolescence to young adulthood. Criminology, 40, 401-434.

Steiger, J.H. (1990). Structural model evaluation and modification: An interval estimation approach. Multivariate Behavioral Research, 25, 173-180.

Stice, E., \& Barrera, M. (1995). A longitudinal examination of the reciprocal relations between perceived parenting and adolescents' substance use and externalising behaviors. Developmental Psychology, 31, 322-334.

Stouthamer-Loeber, M., Loeber, R., Wei, E., Farrington, D.P., \& Wikström, P.H. (2002). Risk and promotive effects in the explanation of persistent serious delinquency in boys. Journal of Consulting and Clinical Psychology, 70, 111-123.

Van der Heijden, P., 't Hart, H., \& Dessens, J. (1997). A parametric bootstrap procedure to perform statistical tests in LCA of anti-social behaviour. In J. Rost \& R. Langeheine (Eds.), Application of latent trait and latent class models in the social sciences (pp. 190202). New York: Waxmann.

Vuchinich, S., Bank, L., \& Patterson, G.R. (1992). Parenting, peers, and the stability of antisocial behavior in preadolescent boys. Developmental Psychology, 28, 510-521.

Woodward, L.J., Fergusson, D.M., \& Horwood, L.J. (2002). Deviant partner involvement and offending risk in early adulthood. Journal of Child Psychology and Psychiatry, 43, 177-190.

Wright, B.R.E., Caspi, A., Moffitt, T.E., \& Silva, P.A. (1999). Low self-control, social bonds, and crime: Social causation, social selection, or both? Criminology, 37, 479-514.

Wright, B.R.E., Caspi, A., Moffitt, T.E., \& Silva, P.A. (2001). The effects of social ties on crime vary by criminal propensity: A life course model of interdependence. Criminology, 39, 321-350.

Manuscript accepted 27 November 2003 